\title{
Genetic diversity for reproductive traits of CMS restorer lines of rice (Oryza sativa L.)
}

\section{Rubaiya Jesmin and M. Abdul Khaleque Mian}

Dept. of Genetics and Plant Breeding, Bangabandhu Sheikh Mujibur Rahman Agricultural University (BSMRAU), Gazipur 1706, Bangladesh

$\bowtie$ rjmin.3119@gmail.com (Jesmin, R.), Published: 25 May 2016.

\begin{abstract}
An experiment was conducted to study genetic divergence in 29 CMS restorer lines of rice. The study was carried out at the experimental farm, Dept. of Genetics and Plant Breeding, Bangabandhu Sheikh Mujibur Rahman Agricultural University, Gazipur during January, 2014 to June, 2014. Genetic divergence was estimated using $D^{2}$ and principal component analysis. PCA showed $71.2 \%$ variation against first Eigen values. From the scattered diagram it was revealed that the genotypes Acc-7386/ SHAKTI-1R, Acc-7394/ACI-1R, Acc-7407/ CHINA-2R, Acc-7404/ HB-8R and Acc-7409/1R-509R were distantly located. Nonhierarchical clustering using co-variance matrix grouped 29 CMS restorer lines of rice into five different clusters. PCO showed that the highest inter genotype distance (2.422) was observed between the genotypes Acc-7386/ SHAKTI-1R and Acc-7394/ACI-1R. The lowest distance (0.458) was observed between the genotypes Acc-7396/ LP-106R and Acc-7397/ LP-108R. The genotypes of cluster II exhibited the highest mean value for 11 out of 21 characters studied followed by cluster $V$ exhibited the highest mean value for 5 out of 21 characters studied. The genotypes of cluster I exhibited the lowest mean value for 8 out of 21 characters studied followed by cluster IV exhibited the lowest mean value for 6 out of 21 characters studied. There were marked variations in intracluster distances, which ranged from 0.000 to 1.066. Considering magnitude of genetic distance, contribution of different characters towards the total divergence, magnitude of cluster means for different characters and performance of the genotypes Acc-7386/SHAKTI-1R, Acc-7394/ ACI-1R, Acc7407/ CHINA-2R, Acc-7404/ HB-8R and Acc-7409/1R-509R might be selected for further hybrid breeding program.
\end{abstract}

Key Words: Eigen value, Cluster means, Divergence, Non-hierarchical clustering and $D^{2}$ analysis

Cite article: Jesmin, R. \& Mian, M. A. K. (2016). Genetic diversity for reproductive traits of CMS restorer lines of rice (Oryza sativa L.). Journal of Bioscience and Agriculture Research, 09(01), 759767.

Article distributed under terms of a Creative Common Attribution 4.0 International License.

\section{Introduction}

Rice (Oryza sativa L.) is a self-pollinated cereal food plant, extensively cultivated in warm climates. It is generally considered as a semi aquatic annual plant, although it could survive as perennial in the tropics and subtropics. Rice is a cereal crop belonging to the family Gramineae (Poaceae) having 
chromosome numbers $2 \mathrm{n}=24$ under the order Cyperales and class monocotyledon. It is self-pollinated crop. The genus Oryza includes a total of 22 to 27 species out of which only two are cultivated. The two cultivated species are Oryza sativa (Asian rice) and 0 . glaberrima (African rice). It consumed exclusively by humans, as it is a staple food for about $50 \%$ of the global population (Ramkumar et al., 2010). Rice is the staple food for at least $63 \%$ of planet inhabitants and contributes on an average $20 \%$ of apparent calorie intake of the world population (Calpe and Prakash, 2007). Per capita daily rice consumptions is about $450 \mathrm{~g}$ in Bangladesh and it provides about $75 \%$ of the calories and $55 \%$ of Proteins in the average daily diet of the Bangladeshi people (Bhuiyan et al., 2002).

Worldwide, rice is cultivated on 166 million hectares and 745 million tons of rough rice is produced at an average productivity of 4.48 tons per hectare and Asia contributes up to $88 \%$ and $91 \%$ of the world's rice area and production, respectively (FAO, 2015). Bangladesh is the fourth largest producer and consumer of rice in the world with an annual production of about 33.5 million tones. Our total cultivable land is 14.85 million hectare whereas rice covered about $77 \%$ of total cropped area (Julfiquar et al., 2009).Area under T.aman is the highest which is about $50.35 \%$ of total rice land and contributes $40.96 \%$ of the total rice production (BBS, 2012). Hybrids may offer to break through the yield ceiling of semi dwarf rice began in 1964. The discovery of CMS line in rice (Athwal and Virmani, 1972) suggested that breeding could develop a commercially viable F1 hybrid. The study on reproductive traits is one of the criteria of parent selection in three line hybrid system.

Asia is traditionally rich in the diversity of rice including the wild progenitors of cultivated rice. The indigenous rice germplasm of Bangladesh is enriched with wide genetic diversity and valuable gene system for yield attributes and adaptability. The Himalayan foot hills including parts of Bangladesh are considered to be the secondary center of diversity of the genus Oryza (Morishima, 1984). Genetic divergence analysis is one of the criteria of parent selection. In three line system $(A / B / R)$ of heterosis breeding in rice, genetic diversity of the lines is very important.

Genetic diversity can be evaluated with morphological and reproductive traits. The $\mathrm{D}^{2}$ technique is based on multivariate analysis developed by Mahalanobis (1936) had been found to be a useful tool in quantifying the degree of divergence in germplasm. Multivariate analysis with $\mathrm{D}^{2}$ technique measures the amount of genetic diversity in a given population in respect of several characters and assesses relative contribution of different components to the total divergence (Zahan et al., 2008). This analysis provides a measurement of relative contribution of different components on diversity both at intra and inter-cluster level and genotypes drawn from widely divergent clusters are likely to produce heterotic combinations and wide variability in segregating generation (Ghafoor et al., 2001).

Considering the above idea in mind the present investigation was undertaken with the following objectives, to study the genetic diversity of reproductive traits among the CMS restorer lines and to identify the superior R line by comparing the reproductive traits.

\section{Materials and Methods}

Experimental site and design: The experiment was conducted at the experimental field of the Dept. of Genetics and Plant Breeding, Bangabandhu Sheikh Mujibur Rahman Agricultural University (BSMRAU), Salna, Gazipur-1706, during January, 2014 to June, 2014. The experimental site is located at the center of Madhupur Tract (24.09' $\mathrm{N}$ latitude and $90^{\circ} 26^{\prime}$ E longitude) having an elevation of $8.4 \mathrm{~m}$ from sea level.The soil type of experimental field belongs to the shallow Red Brown Terrace type under Salna Series of Madhupur Tract (Brammer, 1971). The field is under Agro Ecological Zone (AEZ) 28 which is characterized by silly clay with $\mathrm{pH}$ value of 6.5 . The climate of the experimental site is subtropical characterized by heavy rainfall during May to September and scanty during the rest of the year. The experiment was laid out in a Randomized Complete Block Design (RCBD) with three replications. The whole experimental area was divided into three blocks, representing three replications. Twenty nine treatments were distributed in the experimental unit of each replication through randomization by using the IRRISTAT program. 
Genotypes: The experiment was conducted using 29 CMS restorer lines. The seeds of all varieties were collected from genetic resources center (GRC), Bangabandhu Sheikh Mujibur Rahman Agricultural University (BSMRAU) mentioned in (Table 01).

Collection of data : Data on phenology such as days to $10 \%$ flowering (DFF), days to $50 \%$ flowering (DF), days to maturity (DM), plant height (PH), effective tillers per plant (ETP), total tillers per plant (TTP), Panicle exertion rate (\%) (PER) were recorded in time. At heading stage anther length (AL), anther breadth (AB), filament length (FL), Pollen sterility (\%) (PS), Pollen fertility (\%) (PF) were recorded. After maturity the selected ten hills of each genotype of each plot were harvested to record yield and yield component like Panicle length (PL), number of primary branches per panicle (NPBP), number of secondary branches per panicle (NSBP), filled grains per panicle (FGP), unfilled grains per panicle (UGP), Grain length-breadth ratio, 1000 grain weight (GW) and grain yield per plant (GYP).

Statistical analysis: Genetic diversity was analyzed using GENSTAT 5.13 software program (copyright 1987, Lawes agricultural Trust, Rothamasted Experimental Station, UK). Genetic diversity analysis involves several steps, i.e., estimation of distance between the varieties clustering and analysis of inter-cluster distances. Therefore, more than one multivariate technique are required to represent the results more clearly and it is obvious from the results of many researches (Bashar, 2002; Uddin, 2001; Junned et al., 1988; Ariyo, 1987; Patil et al., 1987; Anand and Rawat, 1984; Dani and Murthv, 1985).

\section{Table 01. Sources of 29 CMS restorer lines of rice genotypes with their origin}

\begin{tabular}{llllll}
\hline Sl. & $\begin{array}{l}\text { Genotypes/Accessions } \\
\text { number }\end{array}$ & Source & Sl. & $\begin{array}{l}\text { Genotypes/Accessions } \\
\text { number }\end{array}$ & Source \\
\hline 01 & Acc-7385/ HB-9R & BSMRAU & 16 & Acc-7400/ MOYNA-R & BSMRAU \\
02 & Acc-7386/ SHAKTI-1R & BSMRAU & 17 & Acc-7401/ SL-8R & BSMRAU \\
03 & Acc-7387/ BHD-1R & BSMRAU & 18 & Acc-7402/ BU-1R & BSMRAU \\
04 & Acc-7388/ BHD-2R & BSMRAU & 19 & Acc-7403/ BU-7R & BSMRAU \\
05 & Acc-7389/ BHD-3R & BSMRAU & 20 & Acc-7404/ HB-8R & BSMRAU \\
06 & Acc-7390/ HERA-2R & BSMRAU & 21 & Acc-7405/ BU-3R & BSMRAU \\
07 & Acc-7391/ HERA-5R & BSMRAU & 22 & Acc-7406/ BU-2R & BSMRAU \\
08 & Acc-7392/ HERA-10R & BSMRAU & 23 & Acc-7407/ CHINA-2R & BSMRAU \\
09 & Acc-7393/ MATAL-R & BSMRAU & 24 & Acc-7408/ CHINA-1R & BSMRAU \\
10 & Acc-7394/ ACI-1R & BSMRAU & 25 & Acc-7409/ 1R-509R & BSMRAU \\
11 & Acc-7395/ LP-70R & BSMRAU & 26 & Acc-7410/ BU-521R & BSMRAU \\
12 & Acc-7396/ LP-106R & BSMRAU & 27 & Acc-7411/ BU-507R & BSMRAU \\
13 & Acc-7397/ LP-108R & BSMRAU & 28 & Acc-7412/ BU-329R & BSMRAU \\
14 & Acc-7398/ GOLD-R & BSMRAU & 29 & Bu dhan-2 & BSMRAU \\
15 & Acc-7399/ DOYEL-R & BSMRAU & & & \\
\hline
\end{tabular}

BSMRAU= Bangabandhu Sheikh Mujibur Rahman Agricultural University

\section{Results and Discussion}

Significant differences among genotypes in respect of reproductive traits are prerequisites of multivariate analysis. The replicated information of the present study of 29 restorer rice genotypes on analysis of variance revealed significant differences among all the genotypes for all the characters studied. A considerable amount of genetic diversity was observed and therefore diversity analysis was carried out through multivariate analysis. The value of ' $V$ ' statistics was showing significant difference among 29 genotypes.

\section{Principal component analysis}

The principal component analysis yielded Eigen values of each principal component axes of ordination of genotypes with the first axes totally accounted for the variation among the genotypes, while five of these with Eigen values above unity accounted for $71.2 \%$. The first two principal axes accounted for $37.6 \%$ of the total variation among the 21 characters describing 29 CMS restorer lines of rice (Table 
02). Quantification of variability from genetic point of view is very scanty that the first axis largely accounted for the variation among the genotype (22.57) followed by second axis (15.04).

Table 02. Eigen values and percentage of variation for corresponding 21 component characters in 29 CMS restorer lines of rice

\begin{tabular}{lccc}
\hline \multicolumn{1}{c}{ Identifier/Characters } & $\begin{array}{c}\text { Eigen } \\
\text { values }\end{array}$ & $\begin{array}{c}\text { \% of total variation } \\
\text { accounted for }\end{array}$ & $\begin{array}{c}\text { Cumulative } \\
\text { percent }\end{array}$ \\
\hline Days to 10\% Flowering & 4.739 & 22.57 & 22.6 \\
Days to 50\% Flowering & 3.159 & 15.04 & 37.6 \\
Plant height & 2.894 & 13.78 & 51.4 \\
Effective tillers per plants & 2.490 & 11.86 & 63.3 \\
Total tillers per plants & 1.676 & 7.98 & 71.2 \\
Panicle exertion rate (\%) & 1.359 & 6.47 & 77.7 \\
Days to maturity & 1.202 & 5.73 & 83.4 \\
Anther length & 0.855 & 4.07 & 87.5 \\
Anther breadth & 0.614 & 2.92 & 90.4 \\
Filament length & 0.440 & 2.10 & 92.5 \\
Pollen fertility (\%) & 0.385 & 1.83 & 94.4 \\
Pollen sterility (\%) & 0.320 & 1.53 & 95.9 \\
Panicle length & 0.261 & 1.24 & 97.1 \\
Primary branches per panicle & 0.205 & 0.97 & 98.1 \\
Secondary branches per panicle & 0.151 & 0.72 & 98.8 \\
Filled grains per panicle & 0.119 & 0.57 & 99.4 \\
Unfilled grains per panicle & 0.082 & 0.39 & 99.8 \\
Grain length-breadth ratio & 0.031 & 0.15 & 99.9 \\
1000 grain weight & 0.015 & 0.07 & 100.0 \\
Grain yield per plant & 0.001 & 0.00 & 100.0 \\
Yield (ton/ha) & 0.000 & 0.00 & 100.0 \\
\hline
\end{tabular}

\section{Construction of scatter diagram}

Based on the values of principal component scores 1 and 2 obtained from the principal component analysis, a two dimensional scatter diagram $\left(Z_{1}-Z_{2}\right)$ using component score 1 as $X$ - axis and component score 2 as Y- axis was constructed, which has been presented in (Figure 01). The position of the genotypes in the scatter diagram was apparently distributed into five groups, which indicated that there exists considerable diversity among genotypes. The scattered diagram for the rice genotype revealed that the genotype number Acc-7386/ SHAKTI-1R, Acc-7394/ ACI-1R, Acc-7407/ CHINA-2R, Acc-7404/ HB-8R and Acc-7409/ 1R-509R were distantly located which suggested that the genotype were more diverged from rest of the genotypes.

\section{Principal coordinate analysis}

Principal coordinate analysis (PCO) was performed on auxiliary of Principal component analysis. This analysis helps in estimating distances $\left(\mathrm{D}^{2}\right)$ for all 630 combinations between pairs of genotypes. The highest inter genotype distance (2.422) was observed between the genotypes Acc-7386/ SHAKTI1Rand Acc-7394/ ACI-1R. 


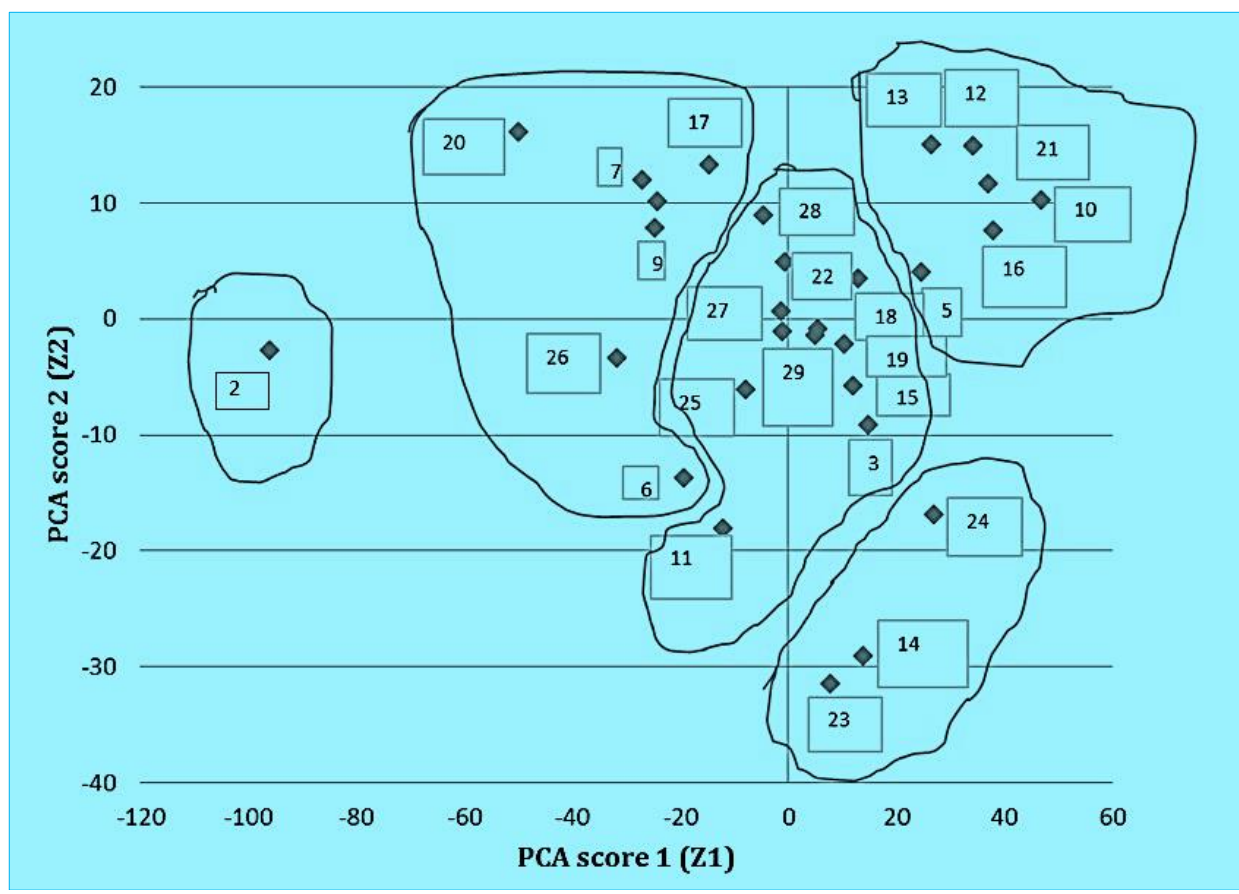

Figure 01. Scatter distribution of 29 CMS restorer lines of rice based on their principal component scores super imposed with clusters.

Table 03. Five of each higher and lower inter genotypic distance $\left(D^{2}\right)$ between pairs of CMS restorer lines of rice

\begin{tabular}{clc}
\hline Sl. Number & \multicolumn{1}{c}{$\begin{array}{c}\text { h highest inter genotypic distances } \\
\text { Genotypes combination }\end{array}$} & Distances \\
\hline 01 & (Acc-7386/ SHAKTI-1R)/ (Acc-7394/ ACI-1R) & 2.422 \\
02 & (Acc-7394/ ACI-1R) / (Acc-7409/ 1R-509R) & 2.19 \\
03 & (Acc-7394/ ACI-1R) / (Acc-7395/ LP-70R) & 2.046 \\
04 & (Acc-7388/ BHD-2R) / (Acc-7404/ HB-8R) & 1.894 \\
05 & (Acc-7385/ HB-9R) / (Acc-7386/ SHAKTI-1R) & 1.863 \\
\hline & 5 lowest inter genotypic distances \\
Sl. Number & Genotypes combination & Distances \\
\hline 01 & (Acc-7396/ LP-106R) / (Acc-7397/ LP-108R) & 0.458 \\
02 & (Acc-7396/ LP-106R) / (Acc-7405/ BU-3R) & 0.498 \\
03 & (Acc-7397/ LP-108R)/ (Acc-7405/ BU-3R) & 0.503 \\
04 & (Acc-7390/ HERA-2R) / (Acc-7399/ DOYEL-R) & 0.537 \\
05 & (Acc-7390/ HERA-2R) / (Acc-7395/ LP-70R) & 0.567 \\
\hline
\end{tabular}

The fifth highest pair distance (1.863) was observed between the genotypes Acc-7385/ HB-9Rand Acc-7386/ SHAKTI-1R. The lowest distance (0.458) was observed between the genotypes Acc-7396/ LP-106Rand Acc-7397/ LP-108R. The fifth lowest pair distance (0.567) was observed between the genotypes Acc-7390/ HERA-2Rand Acc-7395/ LP-70R. The difference between the highest and the lowest inter-genotypes distance indicated the prevalence of variability among the 29 genotypes of CMS restorer line of rice (Table 03).

There were marked variations in intra-cluster distances, which ranged from 0.000 to 1.066 (Table 04). The magnitudes of the intra-cluster distances were not always proportional to the number of genotypes in the clusters. In the present study it was found that although both cluster III \& IV 
composed of the largest number of genotypes (12) \& (7) respectively and their intra-cluster distances were first (1.066) and fourth (0.927) among the five clusters (Table 04).

The intra-cluster distances in all the 5 clusters were more or less low indicated the genotypes within the same cluster were closely related. The highest intra- cluster distances was computed for cluster III (1.066) composed of 12 genotypes followed by the cluster $V(0.978)$ composed of 3 genotypes. However the lowest value $(0.000)$ of intra- cluster distance in cluster II indicated only one genotype (Acc-7386/ SHAKTI-1R) constituted this cluster might have diverged characters, which contributed to the formation of this cluster (Table 04).

Table 04. Average inter cluster distance $\left(D^{2}\right)$ and intra-cluster distance (bold) for 29 CMS Restorer lines of rice

\begin{tabular}{lccccc}
\hline & Cluster I & Cluster II & Cluster III & Cluster IV & Cluster V \\
\hline Cluster I & $\mathbf{0 . 9 5 9}$ & & & & \\
Cluster II & 47.86 & $\mathbf{0 . 0 0 0}$ & & & \\
Cluster III & 8.49 & 40.28 & $\mathbf{1 . 0 6 6}$ & & \\
Cluster IV & 18.25 & 29.63 & 10.86 & $\mathbf{0 . 9 2 7}$ & \\
Cluster V & 15.91 & 46.62 & 12.54 & 20.53 & $\mathbf{0 . 9 7 8}$ \\
\hline
\end{tabular}

\section{Canonical variate analysis}

Statistical distances represent the index of genetic diversity among the clusters. The inter-cluster distances were bigger than the intra-cluster distances suggesting wider genetic diversity among the genotypes of different groups. The inter-cluster distance was maximum between cluster I and II (47.86) while the distance was minimum between cluster I and III (8.49). The maximum values of inter-cluster distance indicated that the genotypes belonging to cluster I was far diverged from those of cluster II. These relations were also reflected in the scatter diagram (Figure02). Basher et al., (2007) reported that inter-cluster distances were larger than intra-cluster distances in a multivariate analysis in rice. The genotypes belonging to clusters III and V having greater intra- cluster distance are recommended for inclusion in a hybridization program as they are expected to produce good segregants.

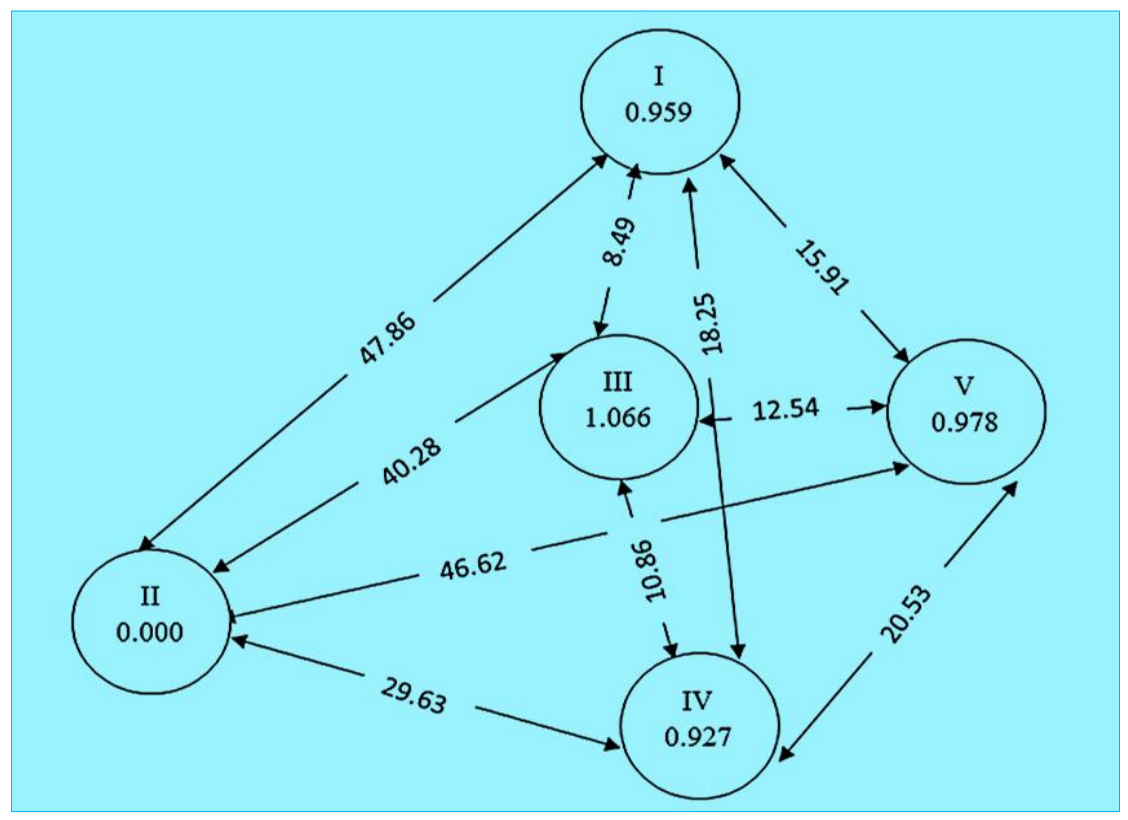

Figure 02. Diagram showing intra and inter cluster distances of twenty nine CMS restorer line of rice. 
Table 05. Distribution of twenty nine CMS restorer lines of rice in five clusters

\begin{tabular}{|c|c|c|c|}
\hline Cluster & Member & Genotypes no. & Local Name \\
\hline $\bar{I}$ & 6 & $\begin{array}{l}5,10,12,13,16 \& \\
21\end{array}$ & $\begin{array}{l}\text { Acc-7389/ BHD-3R, Acc-7394/ ACI-1R, Acc-7396/ LP- } \\
\text { 106R, Acc-7397/ LP-108R, Acc-7400/ MOYNA-R, Acc- } \\
\text { 7405/ BU-3R }\end{array}$ \\
\hline II & 1 & 2 & Acc-7386/ SHAKTI-1R \\
\hline III & 12 & $\begin{array}{l}1,3,4,11,15,18 \\
19,22,25,27,28 \\
\& 29\end{array}$ & $\begin{array}{l}\text { Acc-7385/ HB-9R, Acc-7387/ BHD-1R, Acc-7388/ BHD- } \\
\text { 2R, Acc-7395/ LP-70R, Acc-7399/ DOYEL-R, Acc-7402/ } \\
\text { BU-1R, Acc-7403/ BU-7R, Acc-7406/ BU-2R, Acc-7409/ } \\
\text { 1R-509R, Acc-7411/ BU-507R, Acc-7412/ BU-329R \& } \\
\text { Basmati Indian }\end{array}$ \\
\hline IV & 7 & $\begin{array}{l}6,7,8,9,17,20 \& \\
26\end{array}$ & $\begin{array}{l}\text { Acc-7390/ HERA-2R, Acc-7391/ HERA-5R, Acc-7392/ } \\
\text { HERA-10R, Acc-7393/ MATAL-R, Acc-7401/ SL-8R, Acc- } \\
\text { 7404/ HB-8R \& Acc-7410/ BU-521R }\end{array}$ \\
\hline V & 3 & $14,23 \& 24$ & $\begin{array}{l}\text { Acc-7398/ GOLD-R, Acc-7407/ CHINA-2R \& Acc-7408/ } \\
\text { CHINA-1R }\end{array}$ \\
\hline
\end{tabular}

Table 06. Cluster mean for twenty one characters in CMS restorer lines of rice

\begin{tabular}{lccccc}
\hline Characters & \multicolumn{5}{c}{ Clusters } \\
\hline & I & II & III & IV & V \\
Days to 10\% Flowering & 117.83 & 86.00 & 109.42 & 112.57 & 90.67 \\
Days to 50\% Flowering & 122.50 & 120.00 & 116.58 & 117.29 & 112.33 \\
Plant height & 96.83 & 105.00 & 99.25 & 103.00 & 102.67 \\
Effective tillers per plant & 11.17 & 10.00 & 11.58 & 9.29 & 14.33 \\
Total tillers per plant & 13.83 & 11.00 & 13.58 & 11.14 & 16.67 \\
Panicle exertion rate (\%) & 1.67 & 2.00 & 1.42 & 1.43 & 1.67 \\
Days to maturity & 141.00 & 139.00 & 138.50 & 137.71 & 138.33 \\
Anther length & 78.79 & 78.59 & 76.97 & 76.49 & 81.53 \\
Anther breadth & 11.82 & 11.44 & 11.18 & 11.13 & 12.24 \\
Filament length & 40.52 & 41.22 & 38.52 & 37.78 & 40.52 \\
Pollen fertility (\%) & 82.00 & 87.00 & 85.83 & 83.57 & 87.33 \\
Pollen sterility (\%) & 18.00 & 13.00 & 14.17 & 16.43 & 12.67 \\
Panicle length & 25.47 & 26.90 & 25.73 & 26.67 & 25.97 \\
Primary branches per panicle & 8.50 & 13.00 & 9.08 & 10.14 & 9.00 \\
Secondary branches per panicle & 28.33 & 50.00 & 33.17 & 37.86 & 30.33 \\
Filled grains per panicle & 73.00 & 191.00 & 99.75 & 130.00 & 81.00 \\
Unfilled grains per panicle & 30.00 & 53.00 & 23.17 & 23.57 & 26.67 \\
Grain length-breadth ratio & 3.53 & 4.08 & 3.45 & 3.69 & 3.43 \\
1000 grain weight & 14.83 & 15.00 & 21.58 & 21.00 & 17.67 \\
Grain yield per plant & 26.83 & 65.40 & 43.41 & 47.39 & 51.47 \\
Yield (ton/ha) & 7.17 & 17.00 & 11.67 & 12.57 & 13.67 \\
\hline
\end{tabular}




\section{Non-hierarchical clustering}

Non-hierarchical clustering using co-variance matrix grouped 29 CMS restorer line of rice into five different clusters. These results confirmed the clustering pattern of the genotypes obtained through principal component analysis.So the results obtained through PCA were confirmed by non-hierarchical clustering. Number of genotypes in five clusters ranged from 1 to 12 in different clusters (Table $05)$.The distribution pattern indicated that the maximum number of genotypes (12) was included in cluster III followed by cluster IV (7), cluster I (6), cluster V (3) and minimum genotype constituted of the cluster II (Acc-7386/ SHAKTI-1R).

\section{Intra-cluster mean}

The genotypes in cluster I showed the highest desirable mean value for pollen sterility (\%) (Table 06). Similarly the genotypes in cluster II showed the highest desirable mean value for plant height, panicle exertion rate (\%), filament length. It also showed highest mean value for panicle length, primary branches per panicle, secondary branches per panicle, filled grains per panicle, unfilled grains per panicle, grain length-breadth ratio, grain yield per plant and yield (ton/ha) and lowest mean value for days to $10 \%$ flowering followed by the genotypes in cluster III which showed the highest desirable mean value for 1000 grain weight. The genotypes in cluster IV showed lowest desirable mean value for days to maturity. Finally the genotypes in cluster $\mathrm{V}$ showed the highest desirable mean value for effective tillers per plant, total tillers per plant, anther length, anther breadth, pollen fertility (\%) and grain yield per plant. From the overall discussion it was revealed that in most of the cases genotypes of cluster II showed the maximum values where as in most of the cases the lowest values were found in cluster I \& IV. These results indicated that these characters had the highest contribution towards the divergence among the 29 CMS restorer line of rice. Bidhan et al. (2002) found that days to 50\% flowering, grain length and grain yield per plant were major yield contributing characters to rice genetic diversity.

\section{Conclusion}

Considering genetic diversity for reproductive traits considerable variability was observed among the 29 CMS restorer lines of rice. As per cluster analysis based on 21 characters the 29 CMS restorer lines of rice were grouped into 5 clusters. The genotypes of cluster II exhibited the highest mean value for 11 out of 21 characters studied. The genotypes of cluster I exhibited the lowest mean value for 8 out of 21 characters studied. The scattered diagram for the rice genotype revealed that the genotype number Acc-7386/ SHAKTI-1R, Acc-7394/ ACI-1R, Acc-7407/ CHINA-2R, Acc-7404/ HB-8R and Acc7409/ 1R-509R were distantly located which suggested that the genotype were more diverged from rest of the genotypes. The highest intra- cluster distances was computed for cluster III (1.066) composed of 12 genotypes. However the lowest value (0.000) of intra- cluster distance in cluster II indicated only one genotype (Acc-7386/ SHAKTI-1R) constituted this cluster might have diverged characters, which contributed to the formation of this cluster. Genotypically distant parents are usually able to produce higher heterosis. Considering magnitude of genetic distance, contribution of different characters towards the total divergence, magnitude of cluster means for different characters and performance of the genotypes Acc-7386/ SHAKTI-1R, Acc-7394/ ACI-1R, Acc-7407/ CHINA-2R, Acc-7404/ HB-8R and Acc-7409/ 1R-509R may be considered to perform better if used in hybrid breeding program. For getting precise idea about diversity molecular approach is recommended.

\section{Acknowledgement}

Authors are very much grateful to the Ministry of Science and Technology, Government of Bangladesh for financial support to complete this research.

\section{References}

[1]. Anand, I. J. \& Rawat, D. S. (1984). Genetic diversity, combining ability and heterosis in brown mustard. Indian Journal of Genetics and Plant Breeding, 44(2), 06-07.

[2]. Ariyo, O. J. (1987). Multivariate analysis and choice of parents for hybridization in Okra. Theoretical and Applied Genetic, 74, 361-363. http://dx.doi.org/10.1007/BF00274718 
[3]. Athwal, D. S. \& Virmani, S. S. (1972). Cytoplasmic male sterile and hybrid breeding in rice. International Rice Breeding. IRRI, Manila, Philippines, 615-620.

[4]. Bashar, M. K. (2002). Genetic and Morpho-physiological basis of heterosis in rice (Doctoral dissertation). Digital Archive on Agricultural Theses and Journal. BSMRAU PhD Thesis. Catalog: BSMRAU200202-08.32-33.

[5]. Basher, M. K., Mian, M. A. K., Nasiruddin, M., Nur-E-Elahi., Julfiquar, A. W. \& Rasul, M. G. (2007). Genetic divergence based on morphophysiological characters of some maintainer and restorer lines of rice (Oryza sativa L.). In Proc. Of the 7th Biennial Conference of Plant Breeding and Genetics Society of Bangladesh, Gazipur. p.72.

[6]. BBS (2012). Bangladesh Bureau of Statistics. Statistical Yearbook of Bangladesh. Ministry of Planning, Government of People's Republic of Bangladesh, 2012. p. 511.

[7]. Bhuiyan, N. I., Paul, D. N. R. \& Jabber, M. A. (2002). Feeding the extra millions by 2025challenges for rice research and extension in Bangladesh. A National Workshop on Rice Research and Extension. 29-31 January, 2002, Bangladesh Rice Research institute, Gazipur.

[8]. Bidhan, R., Basu, A. K., Manda, A. B. \& Roy, B. (2002). Genetic divergence in rice (Oryza sativa L.). Genotypes under humid tropic of Andaman based on grain yield and seed characters. Indian Journal of Agricultural Science, 72(2), 84-87.

[9]. Brammer, H. (1971). Soil resources, Soil Survey Project, AGL. SF/Pak. 6, Technical report 3, Bangladesh.

[10]. Calpe, C. \& Prakash, A. (2007). Sensitive and Special Products -a rice perspective. Commodity Market Review. Food and Agriculture Organization of the United Nations, 49-71.

[11]. Chaturvedi, H. P. \& Maurya, D. M. (2005). Genetic divergence analysis in rice (Oryza sativa L.). Advance in Plant Science, 18(1), 349-353.

[12]. Dani, R. G. \& Murthy, B. R. (1985). Genetic divergence and biology of adaptation in Cicerarietinum. Theoretical and Applied Genetics, 69(1), 383-392.

http://dx.doi.org/10.1007/BF00570907

[13]. FAO (2015). Information and reporting system for agriculture- Hybrid rice and its development. Food and Agriculture Organization, United Nations. Retrieved from http://www.fao.org/.

[14]. Ghafoor, A., Sharif, A., Ahmad, Z., Zahid, M. A. \& Rabbani, M. A. (2001). Genetic diversity in blackgram (Vigna mungo L. Hepper). Field Crops Research, 69(2),183-

190. http://dx.doi.org/10.1016/S0378-4290(00)00141-6

[15]. Julfiquar, A. W. \& Rahman, M. H. (2009). Hybrid rice adoption in Bangladesh. Bangladesh Seed Conference and Fair.

[16]. Junned, S. A., Jackson, M. T. \& Catty, J. P. (1988). Diversity in the wild potato species chaeoenseBtt. Euphytica, 37(2), 149-156. http://dx.doi.org/10.1007/BF00036852

[17]. Mahalanobis, P. C. (1936). On the generalized distance in statistics. Proc. Natl. Inst. Sci. India, 2, 49-55.

[18]. Morishima, H. (1984). Wild plant and demonstration. In: Biology of Rice (S Tsunoda and N. Tkahashi, Eds.). Japan Scientific Soc. Press, Tokyo. pp. 3-30.

http://dx.doi.org/10.1016/B978-0-444-99615-2.50006-5

[19]. Patil, S. G., Mairan, N. R. \& Sahu, V. N. (2005). Genetic divergence of traditional rice germplasm accessions. Journal of Soil and Crop Sciences, 15(2), 308-314.

[20]. Ramkumar, G., Biswal, A. K., Mohan, K. M., Sakthival, K., Sivaranjan, A. K. P., Neeraja, C. N., Ram, T., Balachandran, S. M., Sundaram, R. M. \& Prasad M. S. (2010). Identifying novel alleles of rice blast resistance genes Pikh and Pita through allele mining. International Rice Research Notes, 117, 4185.

[21]. Singh, U. K., Mishra, S. B. \& Thakur, R. (1999). Genetic divergence in boro rice. Oryza, 36(1), 76-77.

[22]. Uddin, M. J. (2001). Morphogenetic diversity and gene action in sesame (Sesamumindicum L.) (Doctoral dissertation). Digital Archive on Agricultural Theses and Journal. BSMRAU PhD Thesis. Catalog: BSMRAU200102-08.

[23]. Zahan, M. J., Bhuiyan, M. S. R. \& Hossain, M. S. (2008). Genetic divergence in Oleiferus brassica species. Journal of Sher-e-Bangla Agricultural University, 2(1), 1-6. 